\title{
Follow up of people fitted with hearing aids after adult hearing screening: the need for support after fitting
}

\author{
Ioanis Gianopoulos, Dafydd Stephens, Adrian Davis
}

In the British population only $20-25 \%$ of people who report hearing difficulties possess a hearing aid..$^{1-2} \mathrm{We}$ have proposed that adult hearing screening would increase the use of hearing aids. ${ }^{1-3}$ In three studies conducted in Wales between 1982 and 1992 all people aged 50-65 in four general practices were sent a screening questionnaire on hearing difficulties. Those who reported hearing problems were tested audiometrically and were offered a hearing aid if the average hearing level in their worse ear was worse than $30 \mathrm{~dB}$. Two of these studies showed that this intervention increased by threefold the possession of hearing aids in the target populations. ${ }^{2-3}$ Screening was thus effective in the short term; in this study we examined whether the people fitted with aids in the earlier studies continued to use them long term.

\section{Methods and results}

In 1999-2000 we followed up 116 of the 176 people who had been fitted with hearing aids 8-16 years earlier, in the initial studies. Twenty seven people had died and 33 had moved and could not be traced. Therefore we traced $78 \%$ of those not known to be dead. The 116 patients attended for an interview on the use of their hearing aids. We asked those who had rejected their aids whether they would accept a new one and why they had stopped using their old aid.

Overall, 50 patients (43\%; 95\% confidence interval 34 to 52) were still using their aids and 66 were not. Of the 66 who were not, $47(71 \%)$ accepted the offer of a new NHS aid. Eight of these 47 had stopped using their hearing aid because the aid did not improve their hearing, but they hoped a new one would. The other 39 patients cited cosmetic concerns, handling difficulties, irritation in the ear, or feedback.

We then compared the 116 patients we interviewed with the 33 we could not trace to see if they differed. We found no significant differences in sex, occupation (manual versus non-manual), age, hearing levels at fitting, or answers on two questionnaires used in the initial screening studies: the social hearing handicap index ${ }^{4}$ (a measure of difficulties in understanding speech) and the emotional response scale (a measure of emotional effects of hearing loss extracted from the hearing measurement scale ${ }^{5}$ ).

\section{Comment}

Only $43 \%$ of users in our sample were still using their aids 8-16 years after fitting-lower than we hoped for. This suggests that general hearing screening alone, without continuing support after fitting of hearing aids, would result in many people rejecting their aids. Nevertheless, 47 of the 66 patients who rejected their aids were willing to try a new aid. Thus they acknowledged that they needed help and viewed a new hearing aid as potentially helpful. Thirty nine people rejected their aids for reasons amenable to better training in use of the aid or to smaller hearing aids. With support after fitting and smaller, "in the ear," hearing aids, up to $77 \%$ of the patients (50 plus 39 of the 116) might have continued using their aids. Support, counselling, and small aids are more important than expensive modern technology, as only eight patients stopped using their aids because they did not help. The remaining 39 people had experienced benefit with their old aids and did not need acoustically superior aids.

Contributors: IG contacted and interviewed the patients. DS conceived and planned the study. AD cooordinated the study as part of the overall Health Technology Assessment programme. DS is guarantor.

Funding: This work is part of a project on screening for hearing disability funded by the NHS Health Technology Assessment Programme. Grant number 94/46/01.

Competing interests: None.

1 Davis A. Epidemiology. In: Stephens D, ed. Adult audiology. 6th ed. Oxford: Butterworth Heinemann; 1997:2/3/1-2/3/38.

2 Stephens SD, Callaghan DE, Hogan S, Meredith R, Rayment A, Davis AC. Hearing disability in people aged 50-65: effectiveness and acceptability of rehabilitative intervention. BMJ 1990;300:508-11.

3 Davis A, Stephens D, Rayment A, Thomas K. Hearing impairments in middle age: the acceptability, benefit and cost of detection (ABCD). $\mathrm{Br}$ Audiol 1992;26:1-14.

4 Rosen JK. An evaluation of the English language version of the social hearing handicap index. Scand Audiol 1979;8:111-5.

5 Noble W, Atherley G. The hearing measure scale: a questionnaire for the assessment of auditory disability. J Auditory Res 1970;10:229-50.

(Accepted 22 April)
Welsh Hearing

Institute, University Hospital of Wales, Cardiff CF14 4XW Ioanis Gianopoulos research fellow Dafydd Stephens professor of audiological medicine

MRC-Institute of Hearing Research, University Park, University of Nottingham,

Nottingham NG7 2RD

Adrian Davis professor

Correspondence to: Professor Stephens. wmdds@cf.ac.uk

BMJ 2002;325:471

\section{One hundred years ago}

A note on the teaching of the history of medicine by William Osler, M.D., F.R.S.

Once a week, over a little "beer and baccy," I meet my clinical clerks in an informal conference upon the events of the week. For half an hour I give a short talk on one of the "Masters of Medicine," in which, as far as possible, the original editions of the works are shown.

In the present crowded state of the curriculum it does not seem desirable to add the "History of Medicine" as a compulsory subject. An attractive course will catch the good men and do them good, but much more valuable is it to train insensibly the mind of the student into the habit of looking at things from the historical standpoint, which can be done by individual teachers who themselves appreciate the truth of Fuller's remark:

"History maketh a young man to be old, without either wrinkles or grey hairs; privileging him with the experience of age, without either the infirmities or inconveniences thereof. Yea, it not onely maketh things past present, but inableth one to make a rationall conjecture of things to come. For this world affordeth no new accidents, but in the same sense wherein we call it a new Moon, which is the old one in another shape, and yet no other then what hath been formerly. Old actions return again, furbished over with some new and different circumstances." 